\title{
Interfacial Phenomena Effect on Sand Production Due to Optimized Smart Water with/without the Presence of Nanoparticles
}

\author{
Afshin Bahri 1(D), Ehsan Khamehchi 1,* (D) \\ 1 Department of Petroleum Engineering, Amirkabir University of Technology (Tehran Polytechnic), Tehran, Iran \\ * Correspondence: khamehchi@aut.ac.ir;
}

Scopus Author ID 26657370700

Received: 3.05.2020; Revised: 24.05.2020; Accepted: 25.05.2020; Published: 27.05.2020

\begin{abstract}
Historically, smart water flooding is proved as one of the methods used to enhance oil recovery from hydrocarbon reservoirs. This method has been spread due to its low cost and ease of operation, with changing the composition and concentration of salts in the water, the smart water injection leads to more excellent compatibility with rock and fluids. However, due to a large number of sandstone reservoirs in the world and the increase of the recovery factor using this high-efficiency method, a problem occurs with the continued injection of smart water into these reservoirs a phenomenon happened in which called rock leaching. Indeed, sand production is the most common problem in these fields. Rock wettability alteration toward water wetting is considered as the main cause of sand production during the smart water injection mechanism. During this process, due to stresses on the rock surface as well as disturbance of equilibrium, the sand production in the porous media takes place. In this paper, the effect of wettability alteration of oil wetted sandstones $(0.005,0.01,0.02$ and 0.03 molar stearic acid in normal heptane) on sand production in the presence of smart water is fully investigated. The implementation of an effective chemical method, which is nanoparticles, have been executed to prevent sand production. By stabilizing silica nanoparticles $\left(\mathrm{SiO}_{2}\right)$ at an optimum concentration of $2000 \mathrm{ppm}$ in smart water $(\mathrm{pH}=8)$ according to the results of Zeta potential and DLS test, the effect of wettability alteration of oil wetted sandstones on sand production in the presence of smart water with nanoparticles is thoroughly reviewed. Ultimately, a comparison of the results showed that nanoparticles significantly reduced sand production.
\end{abstract}

Keywords: Smart water; wettability alteration; sand production; Zeta potential; nanoparticles $\left(\mathrm{SiO}_{2}\right)$.

(C) 2020 by the authors. This article is an open-access article distributed under the terms and conditions of the Creative Commons Attribution (CC BY) license (https://creativecommons.org/licenses/by/4.0/).

\section{Introduction}

\subsection{Sand production.}

One of the essential types of oil reservoirs in the world is sandstone reservoirs. The quartz, feldspar, and clay are the main minerals of this type of reservoirs [1]. In sandstone reservoirs, sand production is the biggest problem that we face where sand particles get separated from reservoir rock due to different factors of matrix cement that are not able to hold, imposing high costs on oil companies in the world every year. Its effects result in damage to equipment and well tools, corrosion and erosion of pipelines, plugging the pipelines and wells, disturbance of wellbore stability. An essential issue is the reduction of formation permeability and, consequently, the reduction of oil recovery factor of the reservoir due to the plugging of sand particles in the pore throat [2-4]. 
Generally, sand production occurs when the stress of the particles exceeds the strength of the rock. The rock strength depends on the cement adhesion force, fluid adhesion force, the friction force between the formation particles, and the gravity force of the particles themselves. Particle stresses include stress due to tectonics tension, overburden pressure, drag force due to fluid production applied to the particle, pore pressure, and force due to pressure difference between well and reservoir during production. Therefore, sand production is calculated according to different factors [5-7].

Ranjith et al. al. concluded that the rate of sand production increases with increasing the drag force and decreases with increasing clay content [8]. In unconsolidated sandstone reservoirs with low cementation, poor compression, and high clay content, when water penetrates the formation, and the clay soaks, it reduces the adhesion force between the components, decreases the rock strength, and consolidated sandstone turns to loose sandstone. Therefore, after the water penetration, the critical flow rate that causes the sand production reduced, and sand production becomes easier [5, 5].

Water injection is mainly used to prevent the reservoir pressure drop and to reduce its depletion energy at the time of development and production of the reservoir. Injection of water causes clay swelling in the formation and their migration. Therefore, the adhesion of clay is severely affected. This theory explains that sand production does not occur in wells with zero water production and heavy sand production after water penetration $[6,7,9]$.

Wettability alteration in sandstones is one of the most critical challenges due to their geochemical complication. Generally, sandstone surfaces have a negative electric charge within the natural $\mathrm{pH}$ range of reservoirs. Their wettability can extend to a wide range, from very strong water-wet to very strong oil-wet. Therefore a careful evaluation of the initial wettability of the system is essential to lead to a successful process of wettability alterations [10-11]. One of the factors influencing the formation of particle migration is the particle's surface wettability properties. By experimenting in two-phase flow modes in porous media, it has been concluded that the movement of the surface wetting phase is necessary for the migration of formation particles [12-14].

\subsection{Smart water.}

Regarding the increase in the daily need for energy and the limited number of oil reservoirs in the world, it is necessary to focus on increasing the production from oil reservoirs. Most of the world's oil reservoirs have reached the second half stage of their life, so the production of residual oil in reservoirs has been considered after primary production. In this study, the water injection method is more important than the other EOR methods due to its low cost and ease of application. One of the most effective water EOR methods in the oil industry is smart water injection into the reservoir [15-18].

Before the term smart water, became popular among researchers and carried out flooding operations with this water, they usually used seawater as an injectable source of water to perform the flooding process. For the first time, Bernard has been evaluated the effect of salinity on enhanced oil recovery [19].

Zhang et al. and Rivets et al. found that the salinity of the formation water affected the increase of recovery percentage [20-21]. So, smart water is defined as water which its salinity and ionic composition are artificially synthesized. However, low salinity is defined as water with reduced initial salinity into a proportion. So it can be concluded that low salinity water is also a type of smart water [22-23]. 
In Smart water technology, the change of water injection salinity, as well as the usage of specific ions, changes the reservoir rock wettability and drives it to our desired wettability. One of the conventional methods of measuring the wettability is to measure the contact angle of the surface with the desired fluid in the presence of the other immiscible fluid. Oil wettability classifies the rock from strongly water-wet to strongly oil-wet, according to the contact angles shown in Table 1 [24].

Table 1. Wettability classification in the function of contact.

\begin{tabular}{c|c} 
Contact angle $\left({ }^{\circ}\right)$ & wettability \\
\hline $0-30$ & Strongly-water wet \\
\hline $30-90$ & Water-wet \\
\hline 90 & Neutral wet \\
\hline $90-150$ & Preferentially oil-wet \\
\hline $150-180$ & Strongly oil-wet
\end{tabular}

In this method, the reservoir rock wettability alteration toward more water wetting, which is the desired wettability, is created by disturbing the condition of the ions in the reservoir environment. For this purpose, by the existence of different ions such as $\mathrm{Mg}^{2+}, \mathrm{Ca}^{2+}$, $\mathrm{SO}_{4}{ }^{2-}$ in the composition of injection water with low salinity and change in injection water, ionic power can be used [25-26]. The lower the salinity of the injection water into the reservoir, the greater the effect on increasing oil recovery. The low salinity limit in this method is between 500 to 5000 ppm [22].

Tang et al. reported a change in wettability toward water wetting and an increase in oil recovery by reducing the salt concentration in the water flooding experiment in an oil-brinerock system. They also reported that as a result of low salinity water injection into the core flooding process, the interactions between water and rock surface separate the particles and let them migrate with the fluid stream into the porous media, causing permeability reduction [27].

However, it must be considered in the case of the injected saltwater that is incompatible with fluid and reservoir rock, and some sediments form the reaction between them in the reservoir, which in turn can affect the production process. On the other hand, as the water injection process continues, a phenomenon called rock leaching occurs, which is the most common problem in the field of sand production in sandstone reservoirs. Also, the wettability of the reservoir rock surface can change as a result of these particles being separated [28-29].

Different methods can be used to prevent sand production, and the most important of those are classified into mechanical and chemical categories. One of the effective chemical methods is the use of nanoparticles. Mechanical methods such as gravel pack and slotted liner around the well, as well as methods such as acidizing, polymer and resin injection, short term and cross-sectional methods, are non-economic and sometimes reduce permeability and production. However, nanotechnology has attracted the attention of many researchers in various sciences, including petroleum engineering, because of unique characteristics such as high specific surface area and minimal size. Applications of these methods such as, changing the wettability of the reservoir rock, reduction of interfacial tension (IFT) between water and oil, enhance the recovery and formation damage control. Previous researches have shown that the presence of nanoparticles can reduce the movement of separated minerals from the rock surface and prevent the ionic equilibrium in porous media [30-35].

Huang et al. announced that nanoparticles were used to fix the formation of particles. In their opinion, the best strategy to prevent the migration of particles during production is to fix them in the reservoir [36]. 
Hasannejad et al. used silica oxide to control the formation of particle movement. By using the core flooding tests and injecting silica oxide as stabilizer formation particles, they found that the nanoparticles at $0.1 \mathrm{wt} \%$ concentration could reduce 80 percent of the production of the formation particles. By measuring atomic force microscopic (AFM) and analyzing the results, they found that the injection of Nano-silica increased the surface roughness, which is considered to be the most critical mechanism for preventing the movement of formation particles, as shown in Figure 1 [37].

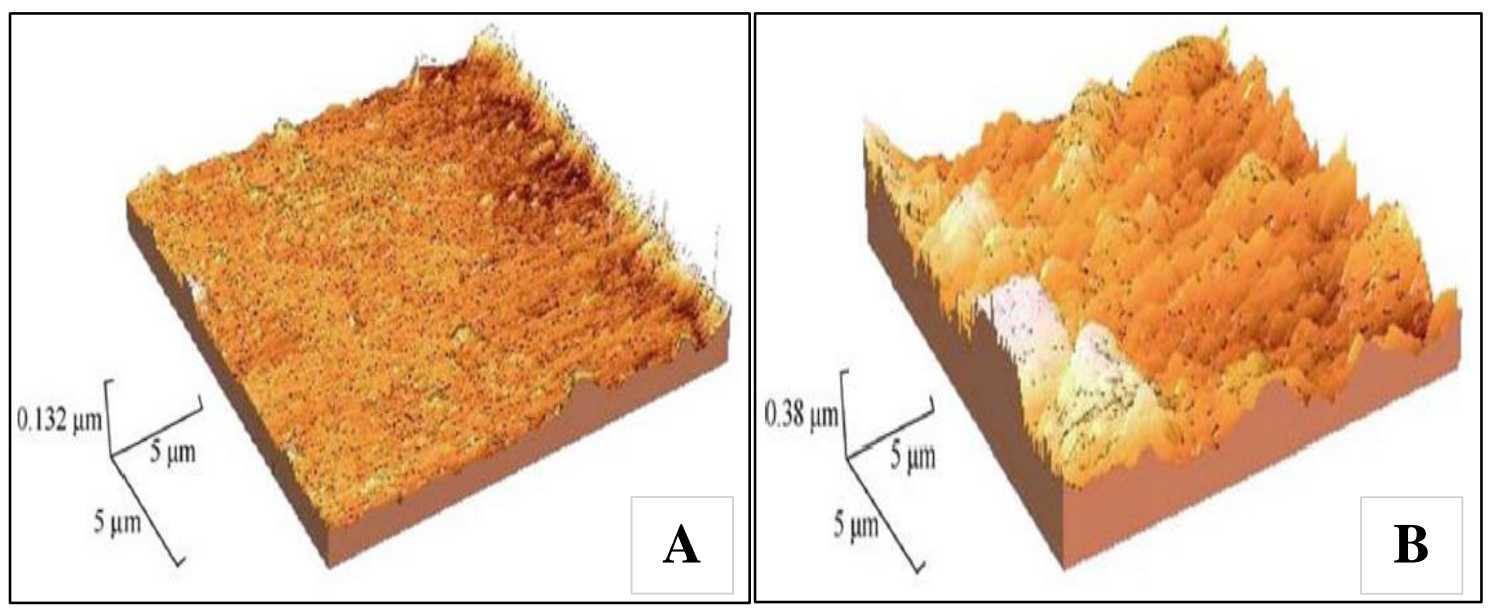

Figure 1. (A) Surface roughness of glass at the base case. (B) The surface roughness of glass coated by 0.1 wt. $\% \mathrm{SiO}_{2}$ Nanofluid [37].

In this paper, a large number of laboratory tests have been done to evaluate the sand production mechanism under different conditions comprehensively. The effect of wettability alternation, which is one of the main mechanisms of increasing production by smart water due to the disturbance of rock surface equilibrium, has been investigated. Numerous tests have also been carried out in the presence of nanoparticles, investigating the effects of wettability change and the rate of sand production in comparison with smart water to improve and economize the water injection.

\section{Materials and Methods}

\subsection{Materials.}

Sandstone cores, salt, deionized water, nanoparticles $\left(\mathrm{SiO}_{2}\right)$, stearic acid, normal heptane, and kerosene were used in this study.

\subsubsection{Minerals.}

For laboratory analysis of sand production, first, the sandstone cores with sand producing ability are made by optimum composition. The composition of rock was reported by the XRF test shown in Table 2.

Table 2. Mineralogy of sand from X-ray fluorescence(XRF) measurements

\begin{tabular}{c|c|c} 
Component & Sand(\%) & Cement(\%) \\
\hline $\mathrm{SiO}_{2}$ & 78.81 & $\mathbf{2 0 . 7 3}$ \\
\hline $\mathrm{Al}_{2} \mathrm{O}_{3}$ & 8.95 & $\mathbf{4 . 1 2}$ \\
\hline $\mathrm{BaO}$ & 0.05 & $\mathbf{0 . 0 7}$ \\
\hline $\mathrm{CaO}$ & 2.42 & $\mathbf{6 1 . 9 1}$ \\
\hline $\mathrm{Fe}_{2} \mathrm{O}_{3}$ & 0.55 & $\mathbf{3 . 2 5}$
\end{tabular}




\begin{tabular}{c|c|c}
\hline Component & Sand (\%) & Cement(\%) \\
\hline $\mathrm{K}_{2} \mathrm{O}$ & 3.16 & $\mathbf{0 . 7 8}$ \\
$\mathrm{MgO}$ & 0.21 & $\mathbf{3 . 2 6}$ \\
\hline $\mathrm{MnO}$ & Negligible & $\mathbf{0 . 2 1}$ \\
\hline $\mathrm{Na}_{2} \mathrm{O}$ & 1.74 & $\mathbf{0 . 3 5}$ \\
\hline $\mathrm{P}_{2} \mathrm{O}_{5}$ & Negligible & $\mathbf{0 . 0 8}$ \\
\hline $\mathrm{SO}_{3}$ & 1.47 & $\mathbf{2 . 3 9}$ \\
\hline $\mathrm{TiO}_{2}$ & 0.05 & $\mathbf{0 . 3 1}$ \\
\hline $\mathrm{Cr}_{2} \mathrm{O}_{3}$ & Negligible & Negligible \\
\hline $\mathrm{LOI}$ & 2.58 & $\mathbf{2 . 4 9}$ \\
\hline $\mathrm{Sr}$ & Negligible & $\mathbf{0 . 0 7}$
\end{tabular}

The core is sliced by cutting machine like is shown in figure 2. The thin sections used in the experiment have an average porosity of $28.22 \%$ and mean permeability of $34.31 \mathrm{md}$.

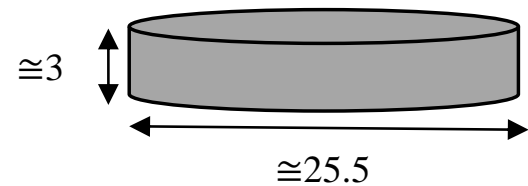

Figure 2. schematic of thin section used for sand production tests

\subsubsection{Brines.}

To obtain the composition of smart water, formation water (related to one of Iran's reservoirs) and seawater (Persian Gulf) were first synthesized in the laboratory by deionized water and laboratory salts (Merck). The deionized water used in the experiments is of a onetime distillation type with Total Organic Contact (T.O.C $<5 \mathrm{ppb}$ ) and Resistivity of $18.2 \mathrm{M} \Omega$ $\mathrm{cm}$. Optimum smart water composition according to the Taguchi algorithm written by Minitab software, and 2, 5, 10, 15 and 20 times diluted seawater was used, and $\mathrm{NaCl}$ salt was used to compensate for the TDS, and compatibility test by formation water was performed at the different ratio in reservoir temperature simulator (oven) at $65^{\circ} \mathrm{C}$. Optimum smart water composition, formation water, and seawater composition are given in table 3 .

Table 3. Composition of formation water, seawater, and smart water.

\begin{tabular}{c|c|c|c} 
Component & $\begin{array}{c}\text { Formation water } \\
\text { weight(g/l) }\end{array}$ & Seawater weight(g/l) & $\begin{array}{c}\text { Smart water } \\
\text { weight(g/l) }\end{array}$ \\
\hline $\mathrm{NaCl}$ & 150 & 28 & 3.364 \\
\hline $\mathrm{KCl}$ & 0 & 0.8 & 0.08 \\
\hline $\mathrm{CaCl}_{2} .2 \mathrm{H}_{2} \mathrm{O}$ & 49.5 & 1.38 & 0.069 \\
\hline $\mathrm{MgCl}_{2} .6 \mathrm{H}_{2} \mathrm{O}$ & 14.5 & 5.5 & 0.275 \\
\hline $\mathrm{NaHCO}_{3}$ & 0.66 & 0.1 & 0.01 \\
\hline $\mathrm{Na}_{2} \mathrm{SO}_{4}$ & 0.403 & 4.4 & 0.22
\end{tabular}

\subsubsection{Other material.}

For the preparation of Nanofluids, $\mathrm{Nano}_{\mathrm{SiO}}$ was used in the experiments. The average particle size of the nanoparticles was $25-50 \mathrm{~nm}$. Stearic acid (with a molar mass of 284.48 $\mathrm{g} / \mathrm{mol}$ and density of $941 \mathrm{~kg} / \mathrm{m} 3$ ) and normal heptane (with a molar mass of $100.21 \mathrm{~g} / \mathrm{mol}$ and density of $684 \mathrm{~kg} / \mathrm{m} 3$ ) was used for oil wetting thin sections, and kerosene oil (with API $45.55^{\circ}$ and viscosity $1.5 \mathrm{cp}$ ) was used for contact angle measurement.

\subsection{Methods.}

\subsubsection{Sand oil wetting.}

For oil wetting thin sections in the experiment, the model oil has been used. Model oil is prepared by adding stearic acid in n-heptane. Stearic acid, which is a fatty acid, has a polar 
and a non-polar head, that sticks to the rock from the polar head and their non-polar head can be dissolved in oil. In this case, London forces are the cause of the interconnection of fatty acid molecules and oil. Stearic acid can dissolve in normal heptane and heavier alkanes. Stearic acid with a molecular formula $\mathrm{CH}_{3}\left(\mathrm{CH}_{2}\right)_{2} \mathrm{COOH}$ by losing hydrogen $(\mathrm{H})$ from its polar head, it sticks to the rock surface and wettability alteration toward oil wetting [38-40]. To investigate the effect of different contact angles, the oil wetted thin sections were created in four concentrations of $0.005,0.01,0.02$ and $0.03 \mathrm{M}$ stearic acid in normal heptane. Finally, the thin sections were placed in an oven for 72 hours at $65^{\circ} \mathrm{C}$ (reservoir temperature simulator). For example, in Figure 3, 0.01 and $0.03 \mathrm{M}$ stearic acid solutions were made (n-Heptane + stearic acid), and thin sections were inserted into the solution.

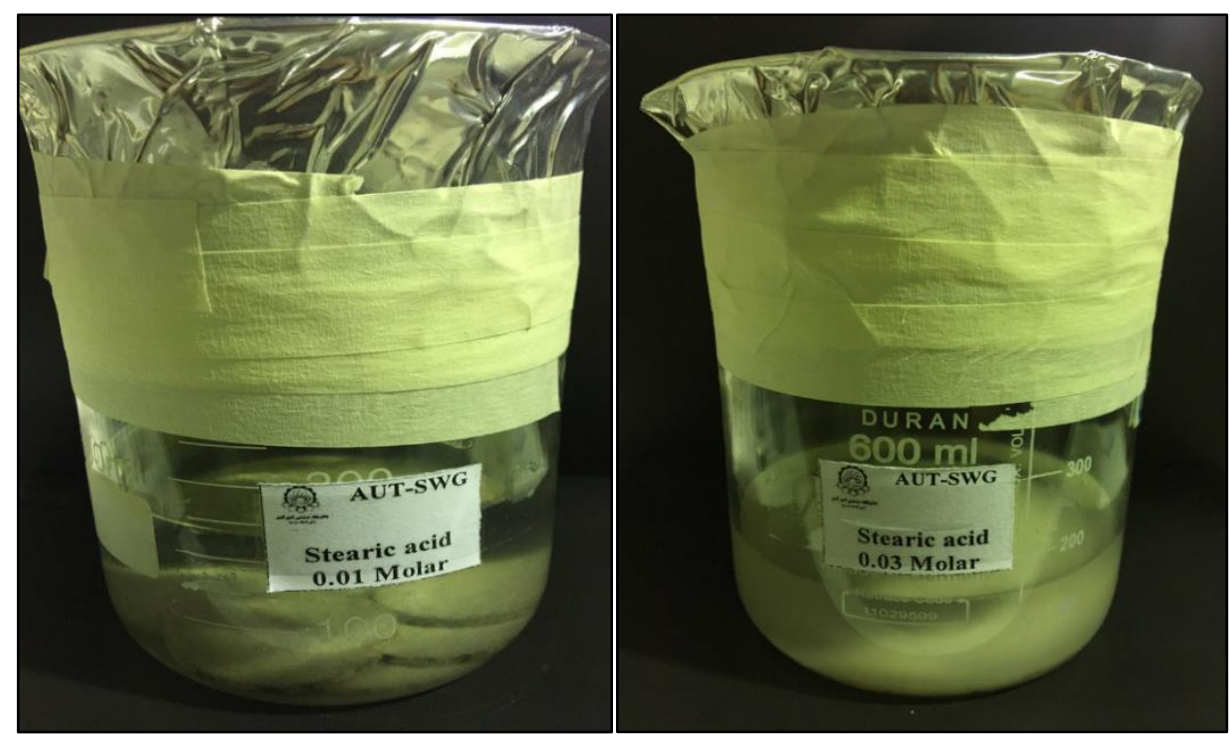

Figure 3. 0.01 and 0.03 molar stearic acid solution (n-Heptane+stearic acid)

\subsubsection{Nanofluid preparation.}

After designing and obtaining the smart water composition, $\mathrm{SiO}_{2}$ nanoparticles were added at various concentrations in the smart water to determine the most stable concentration in the reservoir conditions. First, the smart water was made in a specified volume, the nanoparticles were added to that fluid, the solution was placed in magnetic stirrer for $30 \mathrm{~min}$ (at speed range about 100-1800 rpm) and sonicated (at $24 \mathrm{kHz}$ frequency and $250 \mathrm{~W}$ power) for $1 \mathrm{hr}$. Then placed in the oven for $24 \mathrm{hr}$ at $65^{\circ} \mathrm{C}$, and its stability was examined visually. Based on the two main criteria for Nano-stability in smart water, which are Zeta potential and Dynamic Light Scattering (DLS), Nano 2000ppm at $\mathrm{pH}=8$ of smart water was selected as the optimal Nanofluid [41]. The information of the 2000ppm nanofluid is given in Table 4.

Table 4. Zeta potential and DLS test for 2000ppm $\mathrm{SiO}_{2}$ in optimized smart water

\begin{tabular}{c|c|c|c|c} 
Nano fluid & pH & Zeta potential (mV) & Average diameter(nm) & Stability quality \\
\hline $\mathrm{SiO}_{2}(\mathbf{1 0 0 0} \mathbf{p p m})$ & 8 & -21.4 & 293 & good \\
\hline $\mathbf{S i O 2}(\mathbf{2 0 0 0 p p m )}$ & 8 & -23.9 & 277 & Very good
\end{tabular}

2.2.3. Contact angle measurement.

After the thin sections were oil wetted with concentrations of $0.005,0.01,0.02$ and $0.03 \mathrm{M}$ stearic acid solution, they were inserted into the smart water and $\mathrm{SiO}_{2}$ Nanofluid (2000ppm, $\mathrm{pH}=8$ ). For investigating the rate of sand production and the effects of wettability alteration, 
the thin sections with the solution were put into the oven with $65^{\circ} \mathrm{C}$ for five days, and every 24 hours, we measured the rock contact angle by using kerosene oil with the presence of smart water. The measurement of the contact angle has been taken under the atmospheric condition. The contact angle measurement setup is shown in figure 4 .

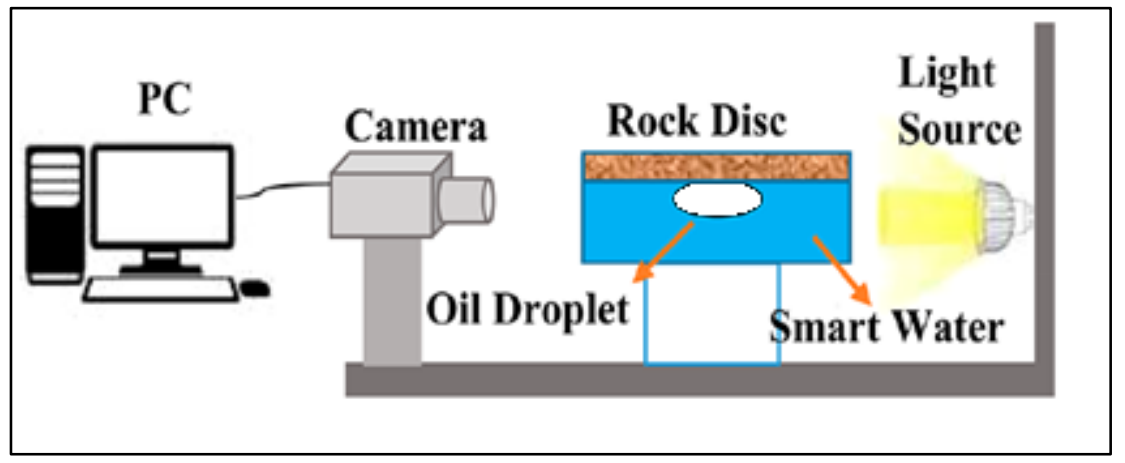

Figure 4. Contact angle apparatus schematic

\subsubsection{Weighing of sand production.}

At the first, the weight of oil wetted thin sections which were completely dried, were measured using a weighing scale with an accuracy of $0.01 \mathrm{~g}$, each thin section was put in its special beaker then every eight beakers were put in the oven at $65^{\circ} \mathrm{C}$. After 24 hours the thin sections were taken out from the smart water fluid and smart water with 2000ppm $\operatorname{Nano}\left(\mathrm{SiO}_{2}\right)$, carefully and by the attention, they were put in the oven with $65^{\circ} \mathrm{C}$ temperature for 2 hours until they dried completely. After the weight measuring again, the thin sections were carried into their special beakers, and then they were put in the oven at $65^{\circ} \mathrm{C}$ temperature. This process repeated for 5 days (120 hours) every 24 hours.

\section{Results and Discussion}

\subsection{Effect of wettability alteration on sand production due to smart water presence.}

One of the main mechanisms to increase production during the injection of smart water into the reservoirs is the wettability alteration to the desired wetting phase, named water wetting. Competition between disjoining pressure (in contrast, the adhesive force of the fluid enters the solid surface and tends to separate the fluid from the surface), capillary pressure, and naphthenic acid removal from the rock surface are defined as the ultimate wettability of the reservoir rock after the smart water injection. Smart water changes disjoining pressure due to the optimum composition and concentration of salts (ionic compounds) by changing electrostatic force and removal of naphthenic acid by ion-exchange mechanism and improves production by changing wettability toward water wetting [42-45]. Now Injecting of smart water into the sandstone reservoirs results in sand production and migration of forming particles. In these experiments, wettability alteration effects of oil wetted sandstones on sand production have been investigated.

At the begging of the experiments, 50cc of smart water (with $\mathrm{pH}=8$ ) was poured into the beakers with oil wetted thin sections at a concentration of $0.005,0.01,0.02$ and 0.03 molar stearic acid solution, which was dried; their weights are given in table 5. 


\begin{tabular}{c|c|c|c|c} 
& \multicolumn{2}{c}{ Table 5. Base weight of thin section in smart water. } & \multicolumn{2}{c|}{$\mathbf{0 . 0 2 M}$} \\
$\begin{array}{c}\text { Oil wetted thin } \\
\text { sections }\end{array}$ & $\mathbf{0 . 0 0 5}$ & $\mathbf{0 . 0 1 M}$ & & \\
\hline Weight(g) & 6.13 & 8.14 & 6.65 & 6.05
\end{tabular}

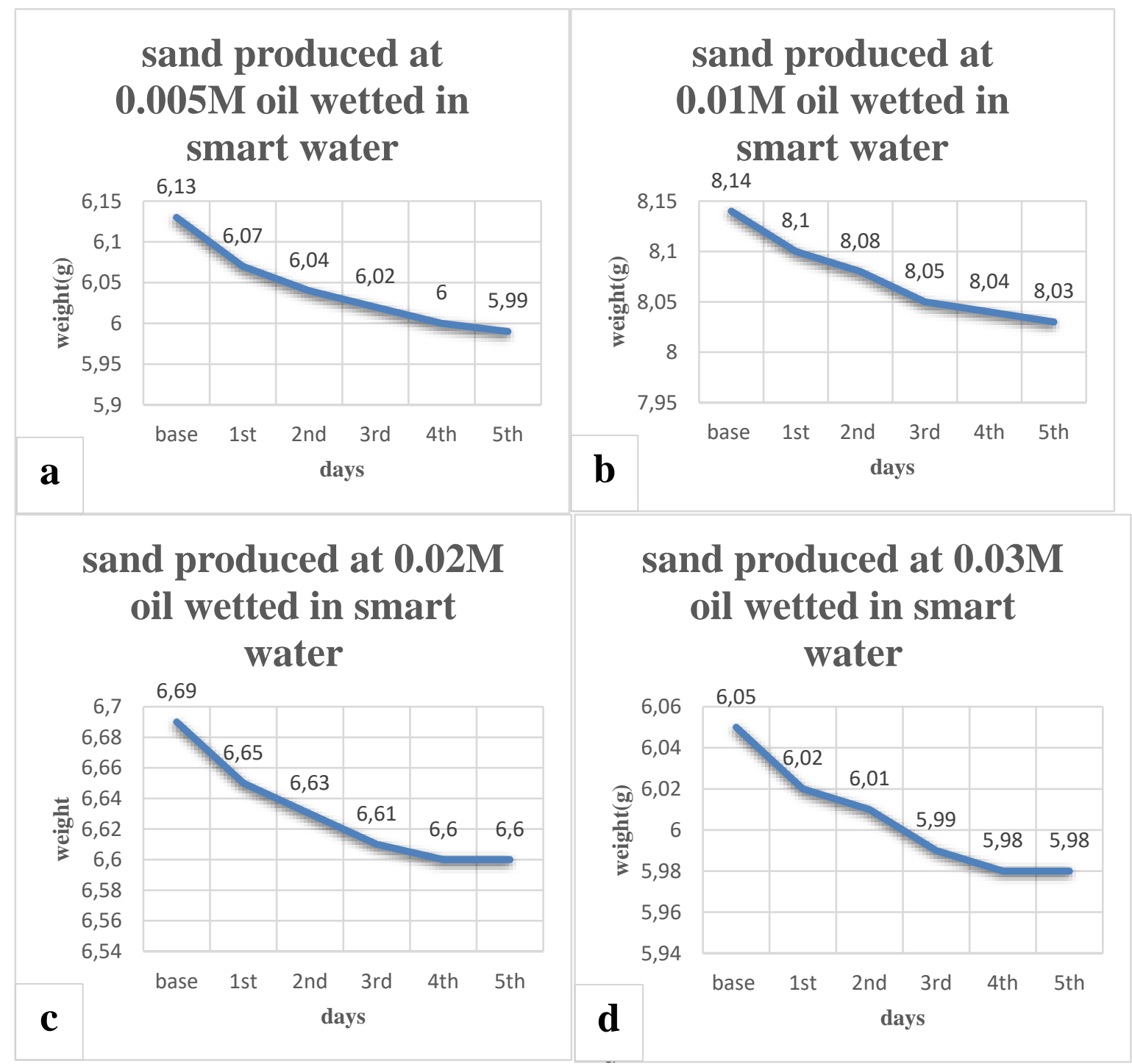

Figure 5. Effect of wettability alteration on sand production in the absence of Nano (a) $0.005 \mathrm{M}$ (b) $0.01 \mathrm{M}$ (c) $0.02 \mathrm{M}$ and (d) $0.03 \mathrm{M}$

After weighing, each thin section was inserted in a specified beaker and placed in a reservoir temperature simulator. Next, we investigate the contact angle and rate of sand production every 24 hours. As can be seen in Figure 5, the highest amount of sand production is from thin sections on the first day (first 24 hours) and decreases with time. Stresses caused by changes in rock wettability in the presence of smart water and electrostatic force changes disturb the equilibrium at the rock surface and causes the sand to be separated from the rock surface and as time passes the changes of wettability alteration (contact angle changes) will get less and sand production will also reduce. There may also be a stabilizing of the grain over time. As a result, initially, loos and unconsolidated grains will be separated. If the stress (induced by any parameter) is greater than the grain adhesion force, the other grains will also be separated from the rock. 
For the thin section, $0.005 \mathrm{M}$, which is less oil wetted than the other thin sections, and according to Table 6 , the base contact angle measurement in the presence of smart water is approximately neutral wet.

Table 6. Base contact angle of oil wetted thin section.

\begin{tabular}{c|c|c|c|c}
$\begin{array}{c}\text { Oil wetted thin } \\
\text { section }\end{array}$ & $\mathbf{0 . 0 0 5 M}$ & $\mathbf{0 . 0 1 M}$ & $\mathbf{0 . 0 2 M}$ & $\mathbf{0 . 0 3 M}$ \\
\hline $\begin{array}{c}\text { Contact } \\
\text { angle(degree) }\end{array}$ & 98.173 & 120.314 & 135.425 & 146.551
\end{tabular}
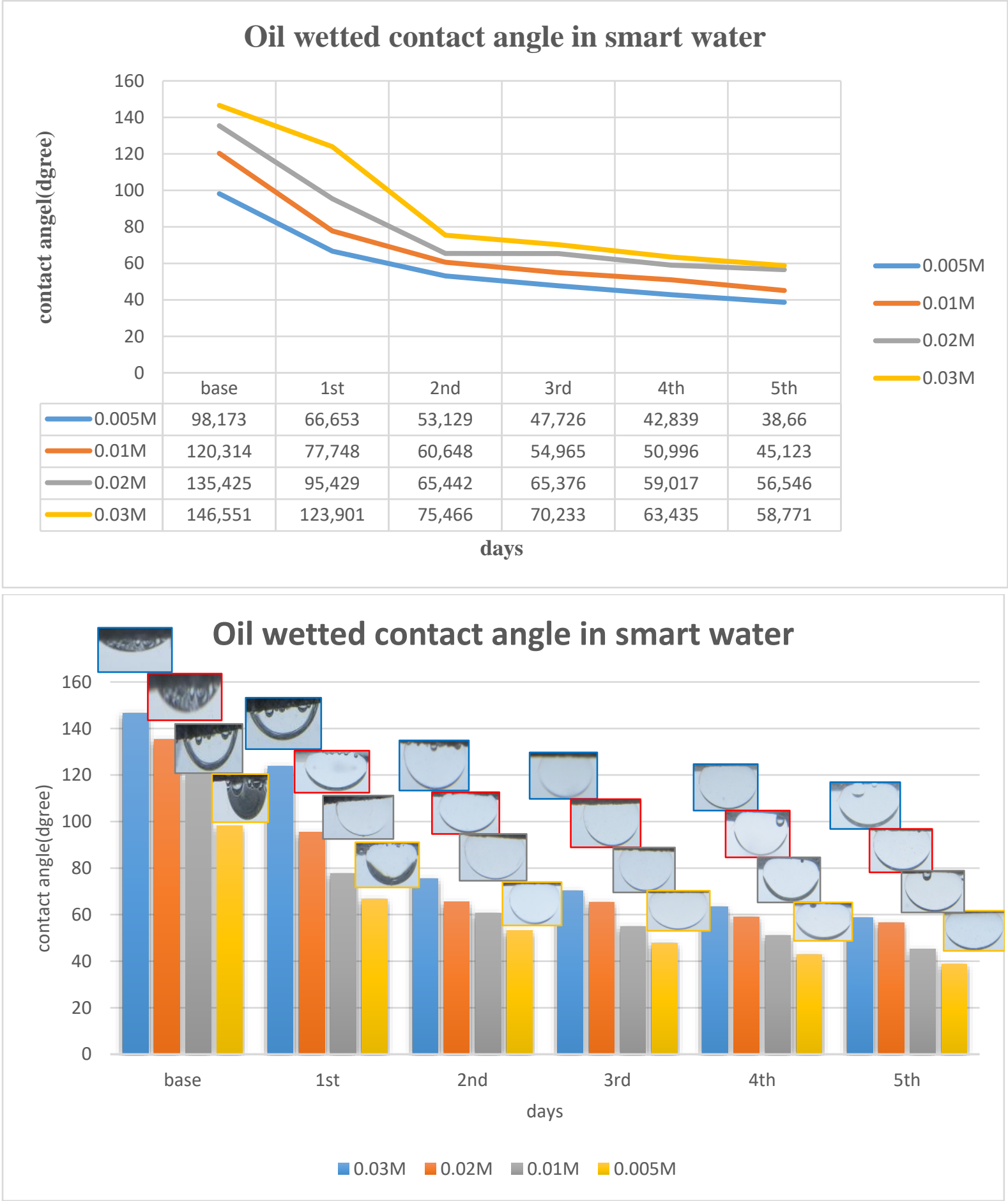

Figure 6. Oil wetted contact angle in smart water

As you can see in Figure 5, most of the final sand production is related to this thin section. As the wettability alternates toward more oil wetting, the wettability alteration toward 
water wetting happened with a slower gradient. The resulting stresses and equilibrium on the rock surface change more slowly, producing less sand. Also, due to the stronger bonding between fatty acids over the oil wetted thin sections surface and also due to strong adhesion, less sand is produced from the rock surface.

Thin section, $0.005 \mathrm{M}$ according to Figure 5, as it is stated earlier, it has the highest sand production than the other thin sections. The amount of sand produced at this stage was $0.14 \mathrm{~g}$, which is $2.284 \%$ of the total thin sections weight. The highest amount of sand produced in this thin section is during the first day, and over time, the rate of sand produced decreases. Also, according to Figure 6, as expected, it has the lowest contact angle after 5 days.

Thin section $0.01 \mathrm{M}$, according to Figure 5, has less sand production than thin section $0.005 \mathrm{M}$, and the amount of sand produced was about $1.351 \%$ of the total thin section weight, and the loss rate in weight is $0.11 \mathrm{~g}$. Most of the sand produced is due to the reasons mentioned in the first day. The trend of the contact angle changes is shown in Figure 6.

Thin section $0.02 \mathrm{M}$, according to Figure 5, has less sand production than thin Section $0.005 \mathrm{M}$ and $0.01 \mathrm{M}$, and its sand production was about $1.345 \%$ of total rock weight, and the loss rate in weight is $0.09 \mathrm{~g}$. The trend of its contact angle changes is shown in Figure 6.

hin section $0.03 \mathrm{M}$, based on Figure 5, produced less sand than other thin sections, and the amount of sand produced at this stage was $0.04 \mathrm{~g}$, which is $1.157 \%$ of the total thin section weight.

\subsection{Effect of wettability alteration on sand production in the presence of nano.}

As mentioned previously, the injection of smart water into the sandstone reservoirs produces sand. Preventing this problem by stabilizing nano- $\mathrm{SiO}_{2}$ in smart water with optimum concentration will increase oil production and reduce the sand production mechanism[4647][5]. Based on the results of the Zeta potential test and DLS, the nanofluid concentration of $2000 \mathrm{ppm}$ was selected. To visualize the effect of the nanoparticles on the rock surface, FESEM images were taken that show the presence of nano-SiO2(2000ppm) in smart water, which can completely cover the rock surface and possibly act as a barrier and reduce stress and prevent the sand production. Figure 7 shows the surface of the rock before contact with the nanofluid. As can be seen, there is no cover or barrier on the rock surface, and all of the sand grains are directly in contact with smart water and can react easily.
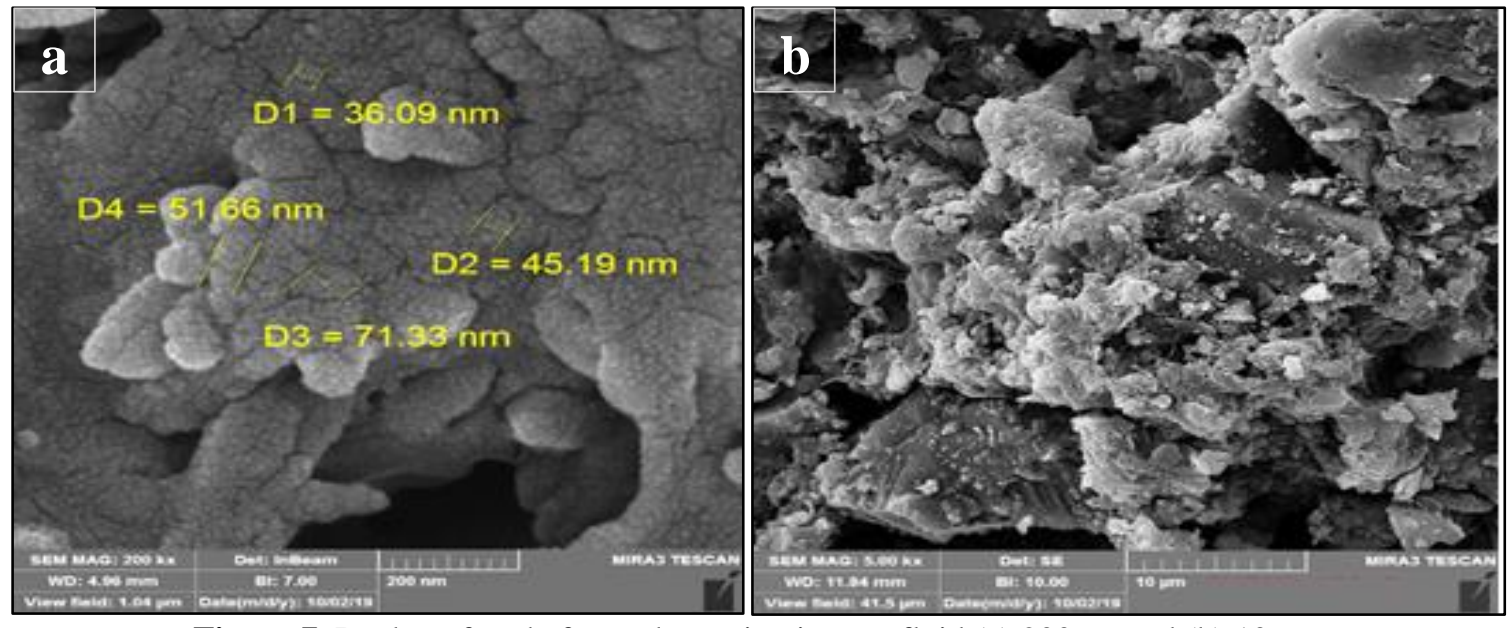

Figure 7. Rock surface before submerging in nanofluid (a) $200 \mathrm{~nm}$ and (b) $10 \mu \mathrm{m}$. 
The rock was exposed to the nanofluid (optimized smart water $+2000 \mathrm{ppm} \mathrm{SiO}_{2}$ nanoparticles at $\mathrm{pH}=8$ ) for 24 hours. 24 hours soaking time is given to nanofluid to have an effect on the rock and to settle on the rock surface. As shown in Figure 8, a layer of nanoparticles coated on the rock surface is present, which reduces sand production.
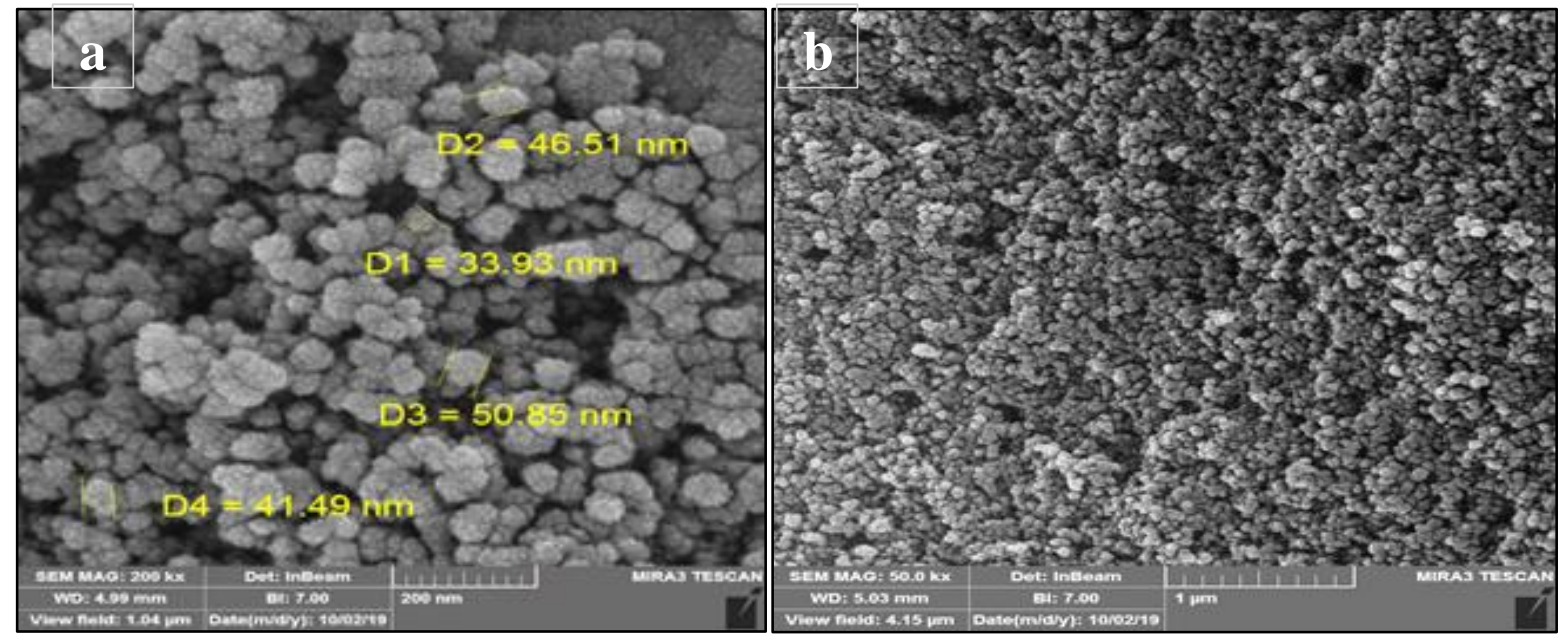

Figure 8. Rock surface after submerging in nanofluid (a) 200nm and (b) $1 \mu \mathrm{m}$.

The presence of nanoparticles in smart water makes the process of reducing wettability alternation faster. Nanoparticles via the surface adsorption process absorbed over the rock surface, and from the other hand as like as the protective layer, prevent the water with low salinity to the rock surface and as a result, the disjoining pressure to oil phase will separate the oil droplets stick over the rock surface and consequently the rock reservoir wettability toward the more water wetting. Disjoining pressure because of Brownian force and electrostatic repulsion that exists among the nanoparticles. As much as the nanoparticles are smaller size, and the concentration of particles is greater, the amount of the pressure will be higher [48-49].

As can be seen in Figure 9, the nanoparticles change with the disjoining pressure at wedge-film and excess pressure due to the accumulation of nanoparticles in the wedge-film causes to overcome the Van der Waals forces and change the wettability [50-51].

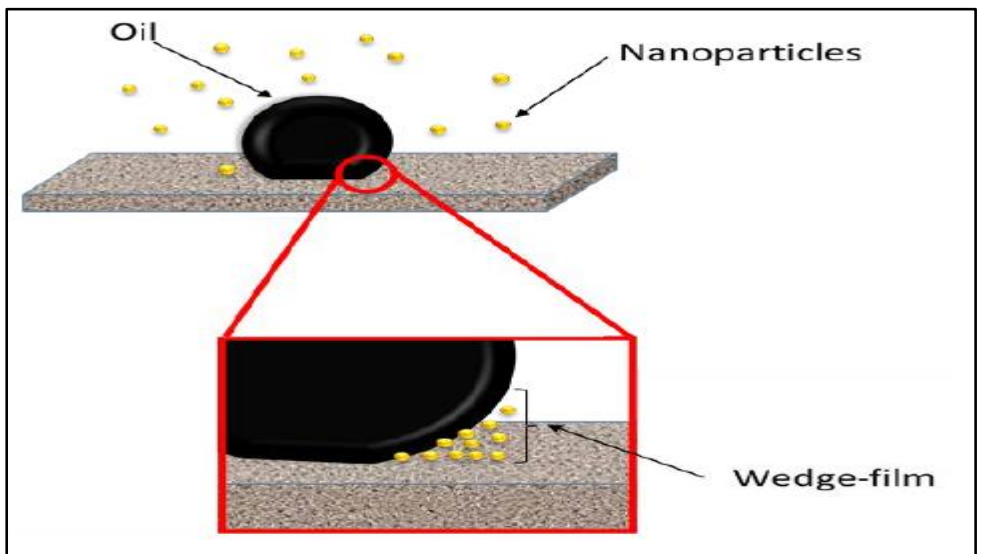

Figure 9. Nanoparticle assembling is wedge film causes to structural disjointing pressure [50].

As in previous experiments, initially stabilized the 2000ppm Sioz-nano in smart water, and 50cc nanofluid poured into the specific beakers, then take the weight of the completely dry thin sections as can be seen in Table 7 . 


\begin{tabular}{c|c|c|c|c}
\multicolumn{7}{c}{ Table 7. Base weight of thin section in smart water } \\
$\begin{array}{c}\text { Oil wetted thin } \\
\text { sections }\end{array}$ & $\mathbf{0 . 0 0 5 M}$ & $\mathbf{0 . 0 1 M}$ & $\mathbf{0 . 0 2 M}$ & $\mathbf{0 . 0 3 M}$ \\
\hline Weight(g) & 6.83 & 7.09 & 6.19 & 6.94
\end{tabular}

Thin sections were placed in their respective beakers, which include smart water and 2000ppm nano-Sio2, and placed at an oven with a temperature of $65^{\circ} \mathrm{C}$ which simulates the temperature of the reservoir, investigation of sand production and contact angle changes every 24 hours for 5 days $(120 \mathrm{hr})$ is executed.

However, the results of experiments in the presence of nanoparticles show that the amount of sand produced is significantly reduced, and after some time (soaking time), the sand production almost stops. The results obtained in these experiments are similar to those of smart water experiments, showing that the lowest sand production is related to the more oil wetted tin section $(0.03 \mathrm{M})$, and the highest amount of sand produced is related to $0.005 \mathrm{M}$ thin section which is almost in neutral wet range.

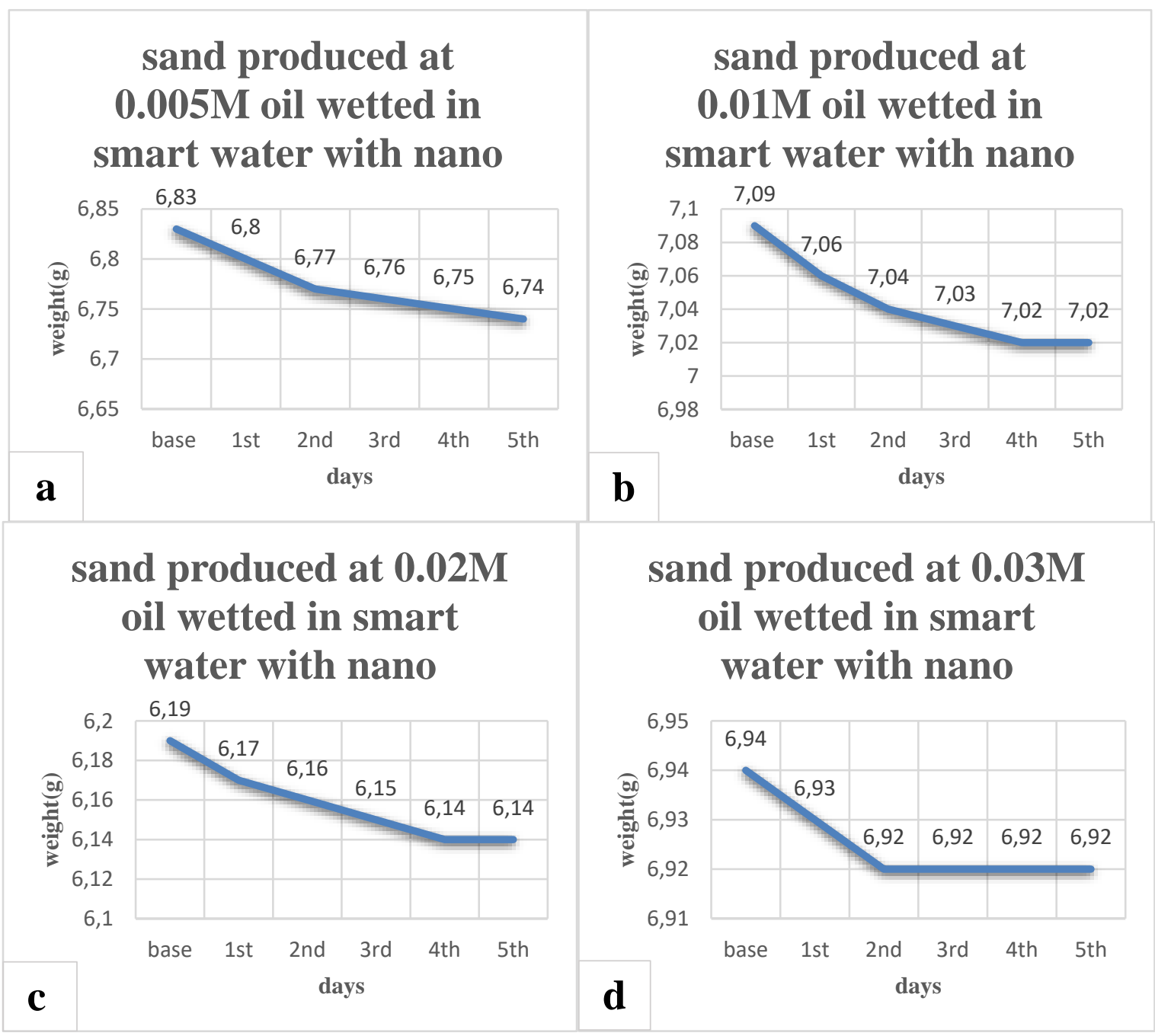

Figure 10. Effect of wettability alteration on sand production in the absence of Nano (a)0.005M (b) $0.01 \mathrm{M}$ (c) $0.02 \mathrm{M}$ and $(\mathrm{d}) 0.03 \mathrm{M}$

Thin section, $0.005 \mathrm{M}$, according to Figure 10, has the highest sand production than the other thin sections, and its sand produced was about $0.09 \mathrm{~g}, 1.317 \%$ of the total tin section weight. The highest amount of sand production in all thin sections are on the first day, and after soaking time and the settling of nanoparticles on the rock surface, the rate of sand production 
is greatly reduced. Also, according to Figure 11, as expected, compared to smart water without nano in all thin sections, the contact angle reduction is faster.

Thin section $0.01 \mathrm{M}$, according to Figure 10, produces less sand than thin section $0.005 \mathrm{M}$, and its sand production is about $0.987 \%$ of the total rock, and its weight loss rate is $0.07 \mathrm{~g}$. The trend of its contact angle changes is shown in Figure 11.

Thin section $0.02 \mathrm{M}$, according to Figure 10, has less sand production than thin section $0.005 \mathrm{M}$ and $0.01 \mathrm{M}$, and its sand production is about $0.807 \%$ of the total rock, and its weight loss rate is $0.05 \mathrm{~g}$ and similar to the thin section $0.01 \mathrm{M}$, sand production stopped at the last 48hours. The trend of its contact angle changes is illustrated in Figure 11.

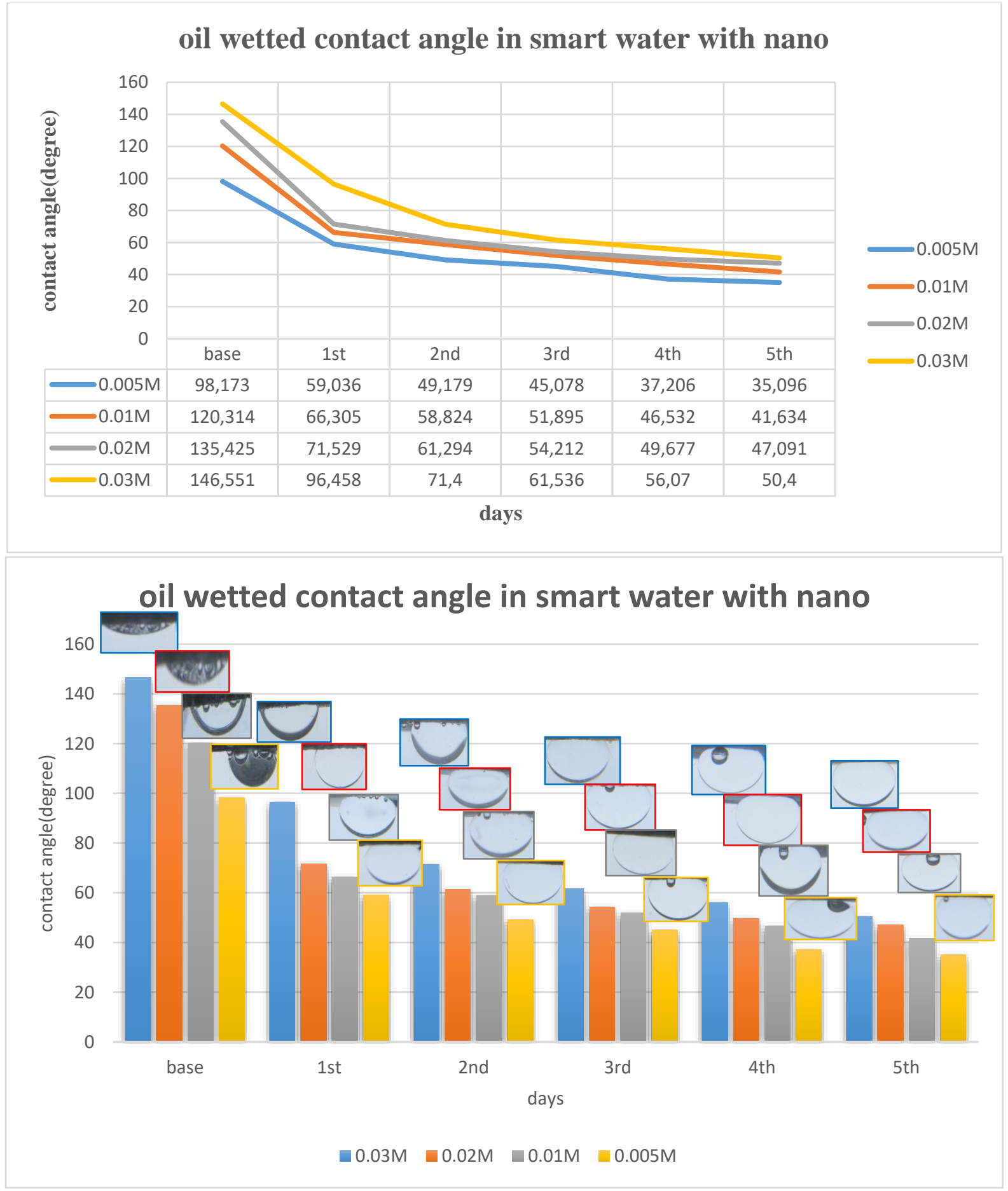

Figure 11. Oil wetted contact angle in smart water with nano 
Thin section, $0.03 \mathrm{M}$, according to Figure (10), has less sand production than other thin sections. The amount of sand produced is about $0.288 \%$ of the total rock, and its weight loss rate is $0.02 \mathrm{~g}$, and as shown in the diagram, sand production stopped at the last 48 hours.

Therefore, according to the results reported in this paper, the stronger the oil wetted sandstone, the lower the amount of sand produced. The results show that smart water containing nanoparticles significantly reduces sand production. After some time, the amount of sand produced is stopped. Also, in Figure 12, a complete comparison of the percentage of sand produced within 5 days between smart water and smart water with nanoparticles (2000ppm $\mathrm{SiO}_{2}$ ) is shown.

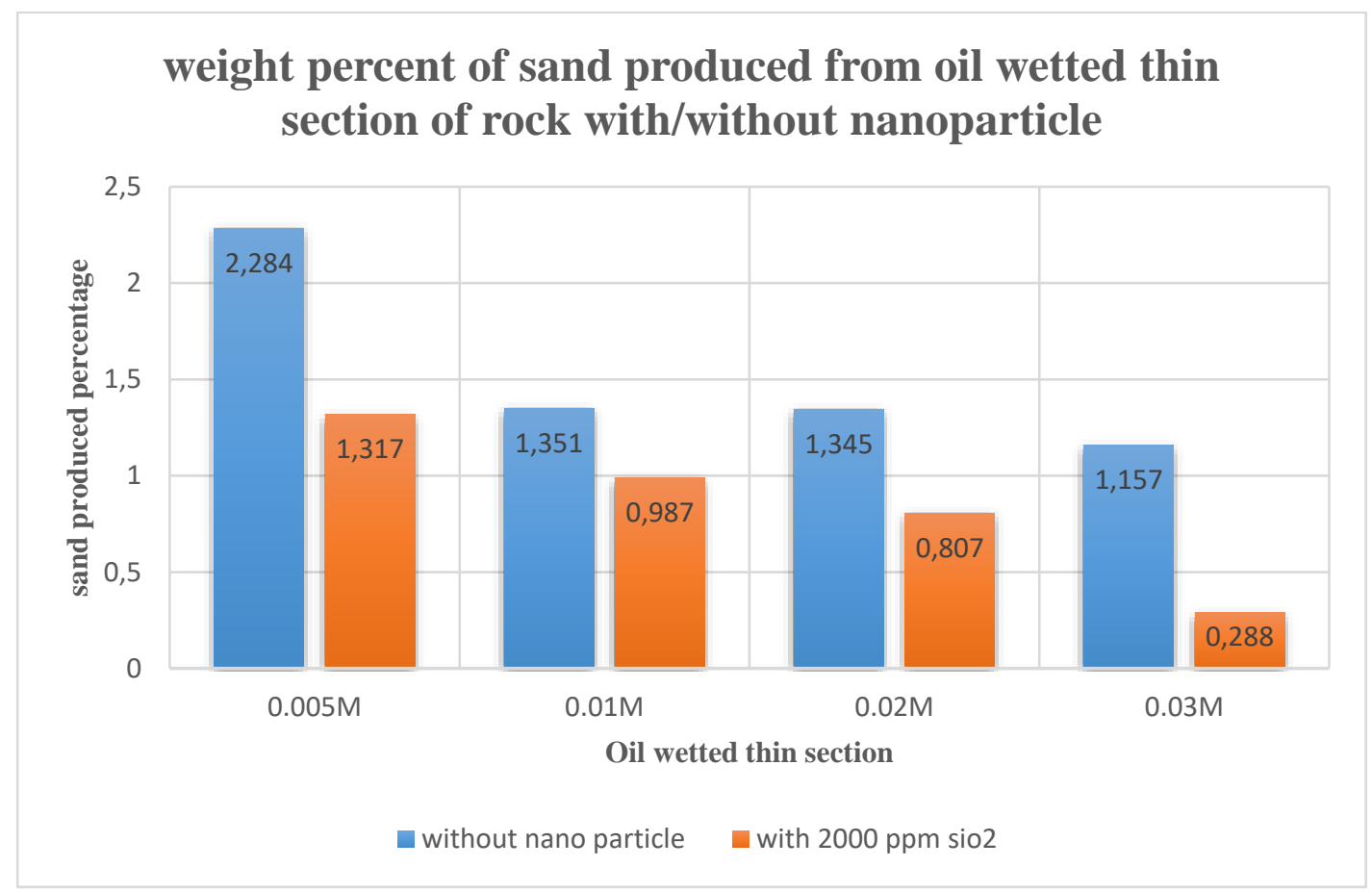

Figure 12. Comparison sand production in different oil wetted thin section

\section{Conclusions}

By injecting smart water and because of the competition between disjoining pressure and capillary pressure and the removal of naphthenic acids, which in turn alters the wettability towards water wetting, the change in wettability is one of the main factors in disturbing the equilibrium at the rock surface which causes sand production.

The rate of sand production in strong oil wetted sandstones $(0.03 \mathrm{M}$ in tests) is less than that of other sandstones. Due to the wettability alternation toward the water wetting with a smoother gradient, the stresses and equilibrium on the rock surface do not change abruptly and produce less sand. And also, because of the strong fatty acid bonds, a layer of adhesion is created on the surface of the rock, causing less sand to be produced.

By adding nanoparticles in smart water at stable and optimum concentrations according to the DLS and zeta potential test results, the amount of sand produced from the rock is significantly reduced due to the coating and roughness, as shown in Figure 8. After the nanoparticle settlement after soaking time, the stone grains will be less exposed to the environment, less stress on the rock surface, and the rock surface will be in better equilibrium conditions.

The most amount of sand produced in smart water is during the first 24hours, in which loose particles are separated and produced from the rock surface. Furthermore, as time passes, 
the stresses decrease to the rock surface, and the equilibrium between the rock and the fluid is maintained, and the rate of sand production reduces. With compared to the fact that in the smart water with nanoparticles, the most sand production is related to the first $24 \mathrm{hr}$, this amount is much lower with the passage of time and complete settling of the particles on the rock enable us to reach a stable point where the sand production stops. According to the results, a reduction of about $46 \%$ of sand production is accomplished.

Finally, injecting smart water with nanoparticles reduce sand production greatly, depending on the contact angles, the wettability alternation towards water wetting due to changes in the disjoining pressure structure at the wedge film and the additional pressure of nanoparticles aggregation at the rock surface, make the Van der Waals force overcome and occur faster. This indicates the improvement of the injection fluid into the reservoir for the EOR process.

\section{Funding}

This research received no external funding.

\section{Acknowledgments}

This research has no acknowledgment.

\section{Conflicts of Interest}

The authors declare no conflict of interest.

\section{References}

1. Bjørlykke, K. Sandstone diagenesis in relation to preservation, destruction and creation of porosity. Development in sedimentology 1988, 41, 555-588, https://doi.org/10.1016/S0070-4571(08)70180-8.

2. Deng, F.; Yan, C.; Jia, S.; Chen, S.; Wang, L.; He, L. Influence of Sand Production in an Unconsolidated Sandstone Reservoir in a Deepwater Gas Field. Journal of Energy Resources Technology 2019, 141, 1-11, https://doi.org/10.1115/1.4043132.

3. Dong, C.; Zhang, Q.; Gao, K.; Yang, K.; Feng, X.; Zhou, C. Screen sand retaining precision optimization experiment and a new empirical design model. Petroleum Exploration and Development 2016, 43, 10821088, https://doi.org/10.1016/S1876-3804(16)30126-4.

4. Ghasemian, J.; Riahi, S.; Ayatollahi, S.; Mokhtari, R. Effect of salinity and ion type on formation damage due to inorganic scale deposition and introducing optimum salinity. Journal of Petroleum Science and Engineering 2019, 177, 270-281, https://doi.org/10.1016/j.petrol.2019.02.019.

5. Moghadasi, R.; Rostami, A.; Hemmati-Sarapardeh, A.; Motie, M. Application of Nanosilica for inhibition of fines migration during low salinity water injection: Experimental study, mechanistic understanding, and model development. Fuel 2019, 242, 846-862, https://doi.org/10.1016/j.fuel.2019.01.053.

6. Zhou, F.; Sun, S. Sand production management for unconsolidated sandstone reservoirs. John Wiley \& Sons, Incorporated 2016, 1-55, https://doi.org/10.1002/9781118961865.fmatter.

7. Al-Awad, M.N.J.; El-Sayed, A.-A.H.; Desouky, S.E.-D.M. Factors Affecting Sand Production from Unconsolidated Sandstone Saudi Oil and Gas Reservoir. Journal of King Saud University - Engineering Sciences 1999, 11, 151-172, https://doi.org/10.1016/S1018-3639(18)30995-4.

8. Ranjith, P.G.; Perera, M.S.A.; Perera, W.K.G.; Wu, B.; Choi, S.K. Effective parameters for sand production in unconsolidated formations: An experimental study. Journal of Petroleum Science and Engineering 2013, 105, 34-42, https://doi.org/10.1016/j.petrol.2013.03.023.

9. Yu, M.; Zeinijahromi, A.; Bedrikovetsky, P.; Genolet, L.; Behr, A.; Kowollik, P.; Hussain, F. Effects of fines migration on oil displacement by low-salinity water. Journal of Petroleum Science and Engineering 2019, 175, 665-680, https://doi.org/10.1016/j.petrol.2018.12.005.

10. Seiedi, O.; Rahbar, M.; Nabipour, M.; Emadi, M.A.; Ghatee, M.H.; Ayatollahi, S. Atomic Force Microscopy (AFM) Investigation on the Surfactant Wettability Alteration Mechanism of Aged Mica Mineral Surfaces. Energy \& Fuels 2011, 25, 183-188, https://doi.org/10.1021/ef100699t.

11. Rao, D.N. Impact of low-cost dilute surfactants on wettability and relative permeability. SPE-99609-MS 2006, 22-26, https://doi.org/10.2118/99609-MS. 
12. Zeinijahromi, A.; Farajzadeh, R.; Bruining, J.; Bedrikovetsky, P. Effect of fines migration on oil-water relative permeability during two-phase flow in porous media. Fuel 2016, 176, 222-236, https://doi.org/10.1016/j.fuel.2016.02.066.

13. Sarkar, A.K.; Sharma, M.M. Fines Migration in Two-Phase Flow. SPE-13932-PA 1990, 42, 646-652, https://doi.org/10.2118/17437-PA.

14. Yu, M.; Zeinijahromi, A.; Bedrikovetsky, P.; Genolet, L.; Behr, A.; Kowollik, P.; Hussain, F. Effects of fines migration on oil displacement by low-salinity water. Journal of Petroleum Science and Engineering 2019, 175, 665-680, https://doi.org/10.1016/j.petrol.2018.12.005.

15. Ahmadi, S.; Hosseini, M.; Tangestani, E.; Mousavi, S.E.; Niazi, M. Wettability alteration and oil recovery by spontaneous imbibition of smart water and surfactants into carbonates. Petroleum Science 2020, https://doi.org/10.1007/s12182-019-00412-1.

16. Morrow, N.; Buckley, J. Improved Oil Recovery by Low-Salinity Waterflooding. SPE-13932-PA 2011, 63, 106-112, https://doi.org/10.2118/129421-JPT.

17. Nowrouzi, I.; Manshad, A.K.; Mohammadi, A.H. Effects of dissolved binary ionic compounds and different densities of brine on interfacial tension (IFT), wettability alteration, and contact angle in smart water and carbonated smart water injection processes in carbonate oil reservoirs. Journal of Molecular Liquids 2018, 254, 83-92, https://doi.org/10.1016/j.molliq.2017.12.144.

18. Rahimi, A.; Honarvar, B.; Safari, M. The role of salinity and aging time on carbonate reservoir in low salinity seawater and smart seawater flooding. Journal of Petroleum Science and Engineering 2020, 187, https://doi.org/10.1016/j.petrol.2019.106739.

19. Bernard, G.G.; Arne, M.; Oil, U. Effect of Flood Water Salinity on Recovery of Oil from Cores Containing Clays. SPE-1725-MS 1967, 8, https://doi.org/10.2118/1725-MS.

20. RivetS., LakeL. W. and PopeG. A. Coreflood investigation of low-salinity enhanced oil recovery. SPE134297-MS 2010, 20, https://doi.org/10.2118/134297-MS.

21. Zhang, Y.; Xie, X. X.; Morrow, N.R. Waterflood performance by injection of brine with different salinity for reservoir cores. SPE-109849-MS 2007, 1-12, https://doi.org/10.2118/109849-MS.

22. Moradi, S.; Isari, A.A.; Bachari, Z.; Mahmoodi, H. Combination of a new natural surfactant and smart water injection for enhanced oil recovery in carbonate rock: Synergic impacts of active ions and natural surfactant concentration. Journal of Petroleum Science and Engineering 2019, 176, 1-10, https://doi.org/10.1016/j.petrol.2019.01.043.

23. Alotaibi, M.B.; Azmy, R.; Nasr-El-Din, H.A. Nasr-El-Din. A comprehensive EOR study using ow salinity water in sandstone reservoirs. SPE-129976-MS 2010, 20, https://doi.org/10.2118/129976-MS.

24. Anderson, W.G. Wettability literature survey-part 3: the effects of wettability on the electrical properties of porous media. SPE-13934-PA 1986, 38, https://doi.org/10.2118/13934-PA.

25. Song, J.; Wang, Q.; Shaik, I.; Puerto, M.; Bikkina, P.; Aichele, C.; Biswal, S.L.; Hirasaki, G.J. Effect of salinity, $\mathrm{Mg} 2+$ and SO42- on "smart water"-induced carbonate wettability alteration in a model oil system. Journal of Colloid and Interface Science 2020, 563, 145-155, https://doi.org/10.1016/j.jcis.2019.12.040.

26. Ali, J.A.; Kolo, K.; Manshad, A.K.; Mohammadi, A.H. Recent advances in application of nanotechnology in chemical enhanced oil recovery: Effects of nanoparticles on wettability alteration, interfacial tension reduction, and flooding. Egyptian Journal of Petroleum 2018, 27, 1371-1383, https://doi.org/10.1016/j.ejpe.2018.09.006.

27. Tang, G.Q.; Morrow, N.R. Influence of brine composition and fines migration on crude oil/brine/rock interactions and oil recovery. Journal of Petroleum Science and Engineering 1999, 24, 99-111, https://doi.org/10.1016/S0920-4105(99)00034-0.

28. Al-Anssari, S.; Barifcani, A.; Wang, S.; Maxim, L.; Iglauer, S. Wettability alteration of oil-wet carbonate by silica nanofluid. Journal of Colloid and Interface Science 2016, 461, 435-442, https://doi.org/10.1016/j.jcis.2015.09.051.

29. Sheng, J.J. Critical review of low-salinity waterflooding. Journal of Petroleum Science and Engineering 2014, 120, 216-224, https://doi.org/10.1016/j.petrol.2014.05.026.

30. Nowrouzi, I.; Manshad, A.K.; Mohammadi, A.H. Effects of ions and dissolved carbon dioxide in brine on wettability alteration, contact angle and oil production in smart water and carbonated smart water injection processes in carbonate oil reservoirs. Fuel 2019, 235, 1039-1051, https://doi.org/10.1016/j.fuel.2018.08.067.

31. Ko, S.; Huh, C. Use of nanoparticles for oil production applications. Journal of Petroleum Science and Engineering 2019, 172, 97-114, https://doi.org/10.1016/j.petrol.2018.09.051.

32. Ameli, F.; Moghbeli, M.R.; Alashkar, A. On the effect of salinity and nanoparticles on polymer flooding in a heterogeneous porous media: Experimental and modeling approaches. Journal of Petroleum Science and Engineering 2019, 174, 1152-1168, https://doi.org/10.1016/j.petrol.2018.12.015.

33. Saxena, N.; Kumar, A.; Mandal, A. Adsorption analysis of natural anionic surfactant for enhanced oil recovery: The role of mineralogy, salinity, alkalinity and nanoparticles. Journal of Petroleum Science and Engineering 2019, 173, 1264-1283, https://doi.org/10.1016/j.petrol.2018.11.002. 
34. Ejtemaee, P.; Khamehchi, E. Experimental investigation of rheological properties and formation damage of water-based. Biointerface Research in Applied Chemistry 2020, 10, 5886-5894, https://doi.org/10.33263/BRIAC104.886894.

35. Ezzati, S.; Khamehchi,. E. Sandstone Reservoir Wettability Alteration Due to Water Softening: Impact of Silica Nanoparticles on Sand Production Mechanism. Biointerface Research in Applied Chemistry 2020, 5, 6328-6342, https://doi.org/10.33263/BRIAC105.63286342,

36. Huang, T.; Crews, J.B.; Willingham, J.R. Nanoparticles for formation fines fixation and improving performance of surfactant structure fluids. IPTC-12414-MS 2008, 1-10, https://doi.org/10.2523/IPTC12414-MS.

37. Hasannejad, R.; Pourafshary, P.; Vatani, A.; Sameni, A. Application of silica nanofluid to control initiation of fines migration. Petroleum Exploration and Development 2017, 44, 850-859, https://doi.org/10.1016/S1876-3804(17)30096-4.

38. Hansen, G.; Hamouda, A.A.; Denoyel, R. The effect of pressure on contact angles and wettability in the mica/water/n-decane system and the calcite+stearic acid/water/n-decane system. Colloids and Surfaces A: Physicochemical and Engineering Aspects 2000, 172, 7-16, https://doi.org/10.1016/S0927-7757(99)004987.

39. Rezaei Gomari, K.A.; Hamouda, A.A. Effect of fatty acids, water composition and $\mathrm{pH}$ on the wettability alteration of calcite surface. Journal of Petroleum Science and Engineering 2006, 50, 140-150, https://doi.org/10.1016/j.petrol.2005.10.007.

40. Fowkes, F.M. Surface effects of anisotropic London dispersion forces in n-alkanes. The Journal of Physical Chemistry 1980, 84, 510-512, https://doi.org/10.1021/j100442a011.

41. Jackson, M.D.; Al-Mahrouqi, D.; Vinogradov, J. Zeta potential in oil-water-carbonate systems and its impact on oil recovery during controlled salinity water-flooding. Scientific Reports 2016, 6, 1-13, https://doi.org/10.1038/srep37363.

42. Xie, Q.; Saeedi, A.; Pooryousefy, E.; Liu, Y. Extended DLVO-based estimates of surface force in low salinity water flooding. Journal of Molecular Liquids 2016, 221, 658-665, https://doi.org/10.1016/j.molliq.2016.06.004.

43. Ju, B.; Fan, T. Wettability Alteration and Its Effects on Production in Water Flooding. Petroleum Science and Technology 2012, 30, 1692-1703, https://doi.org/10.1080/10916466.2011.639589.

44. Bergeron, V.; Radke, C.J. Equilibrium measurements of oscillatory disjoining pressures in aqueous foam films. Langmuir 1992, 8, 3020-3026, https://doi.org/10.1021/la00048a028.

45. Morrow, N.R. Wettability and Its Effect on Oil Recovery. SPE-13932-PA 1990, 42, 1476-1484, https://doi.org/10.2118/21621-PA.

46. Elazab, H.A.; El-Idreesy, T.T. Optimization of the catalytic performance of $\mathrm{Pd} / \mathrm{Fe} 3 \mathrm{O} 4$ nanoparticles prepared via microwave-assisted synthesis for pharmaceutical and catalysis applications. Biointerface Research in Applied Chemistry 2018, 9, 3794-3799, https://doi.org/10.33263/BRIAC91.794799.

47. Aghajanzadeh, M.R.; Ahmadi, P.; Sharifi, M.; Riazi, M. Wettability modification of oil-wet carbonate reservoirs using silica-based nanofluid: An experimental approach. Journal of Petroleum Science and Engineering 2019, 178, 700-710, https://doi.org/10.1016/j.petrol.2019.03.059.

48. Youssif, M.I.; El-Maghraby, R.M.; Saleh, S.M.; Elgibaly, A. Silica nanofluid flooding for enhanced oil recovery in sandstone rocks. Egyptian Journal of Petroleum 2018, 27, 105-110, https://doi.org/10.1016/j.ejpe.2017.01.006.

49. El-Diasty, A.I.; Aly, A.M. Technical, and P. Services. Understanding the Mechanism of Nanoparticles Applications in Enhanced Applications of Nanoparticles in Eenhance oil recovery. SPE-175806-MS 2015, 1-19, https://doi.org/10.2118/175806-MS.

50. Kondiparty, K.; Nikolov, A.; Wu, S.; Wasan, D. Wetting and Spreading of Nanofluids on Solid Surfaces Driven by the Structural Disjoining Pressure: Statics Analysis and Experiments. Langmuir 2011, 27, 33243335, https://doi.org/10.1021/la104204b.

51. Wasan, D.; Nikolov, A.; Kondiparty, K. The wetting and spreading of nanofluids on solids: Role of the structural disjoining pressure. Current Opinion in Colloid \& Interface Science 2011, 16, 344-349, https://doi.org/10.1016/j.cocis.2011.02.001. 